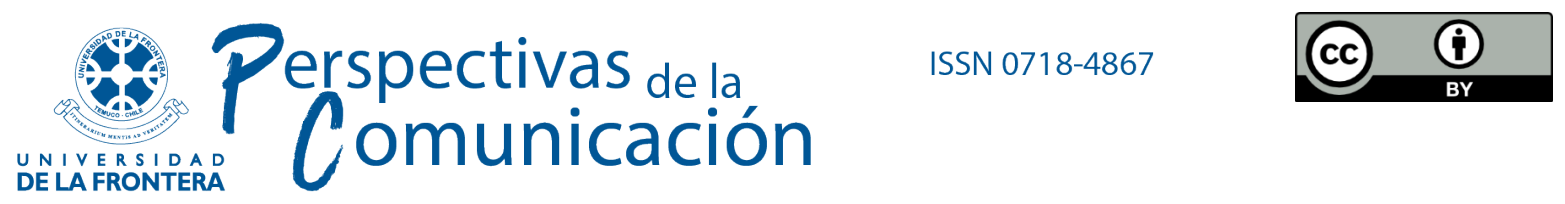

Artículo

\title{
DE LA ARGENTINA SECRETA A LA EMERGENCIA JUVENIL. ANÁLISIS CULTURAL Y POLÍTICA EN LA REVISTA PERONISTA LÍNEA (1980-1982)
}

https://doi.org/oO.0OO/COO-202O-O1

\author{
Dr. Eduardo Raíces \\ Universidad de Buenos Aires, Facultad de Ciencias Sociales. Consejo Nacional de Investigaciones Científicas y \\ Técnicas. Ciudad Autónoma de Buenos Aires, República Argentina \\ e_raices@hotmail.com \\ ORCID: https://orcid.org/o000-0001-6299-0968
}

Recibido el 30 de septiembre de 2019

Aceptado el 27 de abril de 2020

\section{Resumen}

El presente artículo contempla críticamente la tematización cultural en la revista peronista Línea durante la última dictadura militar argentina, en el periodo 1980-1982. La revista surge para contribuir a la rearticulación política del "campo nacional”, conformado desde su discurso por el justicialismo y otros partidos afines, desde una perspectiva de defensa y recuperación del estado de derecho, de repulsa a los "extremismos" y, en particular, de oposición a la dictadura. Pero Línea publicó también en sus páginas análisis, reportajes y ensayos sobre cultura, cultura popular y medios, con la intención de dar cuenta de los componentes de la "cultura nacional", que presentaba opuesta y amenazada por el mercantilismo impuesto por el régimen castrense. Según se señala, esta postura, como estrategia intelectual para convocar voces favorables al discurso de la revista desde el campo cultural, promovió la convivencia heterogénea en sus páginas de visiones de orden tradicional con otras imbuidas por los debates recientes que hacían a la ampliación del canon cultural letrado, la discusión sobre la influencia de los medios en la vida social y de la potencialidad cultural de estos. Asimismo, la revista en similar sintonía reseñó y dio voz a 
expresiones de la cultura juvenil urbana de clases medias como la música rock y las revistas "subte", bajo el entendimiento de que su dinamismo, a la par que original, mostraba un potencial que debía ser contemplado en la perspectiva de la movilización política resurgente desde principios de los años 80, de resultas de la crisis del orden dictatorial.

Palabras clave: cultura, dictadura, peronismo, prensa. 


\title{
FROM THE SECRET ARGENTINA TO YOUTH EMERGENCE. CULTURAL ANALYSIS AND POLITICS IN PERONIST MAGAZINE LÍNEA (1980-1982)
}

\begin{abstract}
This article makes a critical study of the cultural approach of the peronist political magazine Linea, during the last argentine dictatorship (1976-1983). The period covered is 1980-1982, in wich the magazine appears to support the reorganization of the "campo nacional", integrated by the Partido Justicialista and other related political parties, to oppose right and left "extremisms" and, in particular, to the dictatorship, in favor of the rule of law. But also Línea promoted the inclusion of analysis, interviews and essays dealing with cultural contents, especially popular culture and media, to contribute to define a "national culture", seen as opposing and threatened by the economic liberalization imposed by the military regime. It is argued that this intellectual strategy to get cultural voices close to the political discourse of the magazine led to the coexistence of a traditional-cultural approach with other perspectives, more influenced by contemporary debates on cultural canon, popular culture, social influence of media and the assessment of its cultural potential in authoritarian contexts. Also, that Línea included in its pages urban cultural middle class youth expressions, like rock music and self-produced "subte" magazines, on the basis of their original significance; but, also, this practices and products were considered as indicative of a social activation, in the context of recovered political mobilization from the early eighties, as a result of the progressive regime crisis.
\end{abstract}

Keywords: culture, dictatorship, Peronism, press. 


\section{Introducción}

El presente artículo se aplica a indagar los contenidos relacionados con la tematización cultural en la revista de identificación peronista Línea durante la última dictadura militar argentina (1976-1983). Pretende, de este modo, avanzar en la caracterización de la esfera cultural desde el peronismo en el periodo, prácticamente no contemplada en la literatura académica, pese a la centralidad de este actor político y también del quehacer cultural en los procesos de disidencia y oposición al régimen (Novaro y Palermo, 2003; Diego, 2003). Este medio surge en 1980 con el objetivo de aportar desde la crónica y análisis político, económico y cultural, a la rearticulación partidaria del peronismo y de las fuerzas políticas afines bajo el significante del "campo nacional", en oposición a la dictadura. Se consolidará como una de las publicaciones más significativas en difusión y ventas, merced a su fuerte tono crítico. Ello en el marco del recomienzo de la actividad política a partir de la crisis del régimen y de los infructuosos intentos de este de negociar con los principales actores partidarios instancias para su continuidad. Con la salvedad de alguna mención aislada, esta publicación no había sido estudiada con anterioridad. Hemos avanzado en tal sentido a través de contribuciones precedentes que desde el campo académico apuntaron a dar cuenta de su relevancia histórica (Raíces, 2012; Raíces y Borrelli, 2016; Borrelli y Raíces, 2018; Raíces, 2019), y la actual pretende proseguir tal labor.

Aquí abordaremos el discurso sobre la producción simbólica propuesto por la revista. Este cobra importancia en el contexto más general de su discursividad política. En tanto, como veremos, Línea se asigna un cometido intelectual movilizador, que incluye la valoración de contenidos y prácticas que compondrían la "cultura nacional", la convocatoria a algunos de sus artífices y también la discusión de los asociados a la esfera oficial y la industria cultural tal como se desarrolló durante la dictadura. A los fines considerados, el corpus de la revista a contemplar abarca el conjunto de notas donde se abordan cuestiones culturales, publicadas desde su apariciónhasta el número 22, que coincideen el extremo final de la periodización con el desenlace del conflicto bélico por las islas Malvinas, a mediados de 1982. Esta selección se justifica en razón de que, tras la conflagración, la dictadura pierde aceleradamente su consenso social residual y se acelera una activación política (Novaro y Palermo, 2003: 461-465; Canelo, 2008: 12-13) que induce en la revista una reducción ostensible de la tematización cultural dentro de sus contenidos, en favor de las cuestiones de coyuntura (Raíces, 2012; Raíces, 2019). 
A tal fin, dividimos el artículo en apartados de descripción del medio y de situación contextual, de análisis del corpus contemplado y de las respectivas conclusiones.

\section{La revista Línea: unir al "campo nacional" contra la dictadura}

Línea lanzó su edición inicial en junio de 1980 y mantuvo su existencia hasta principios de la década siguiente. Su formato fue el de un mensuario de actualidad política con distribución nacional destinado a un público amplio, de identificación peronista. Fue dirigida por el intelectual revisionista José María “Pepe" Rosa ${ }^{1}$ y contó con un nutrido staff, con periodistas profesionales, escritores, intelectuales y humoristas gráficos, con alto grado de rotación. Entre ellos, para la actualidad política César Seoane Cabral, Rodolfo Audi, Oscar Cardoso, Carlos Campolongo y Ricardo Contesti (bajo anonimato) entre otros; Osvaldo Granados y Claudio Bazán se encargaron del análisis económico, mientras que Pascual Albanese y Enrique Oliva lo hacían sobre temas internacionales y Osvaldo Pepe sobre Deportes. Eran colaboradores eventuales el historiador Salvador Ferla y el periodista Mario Wainfeld. El reconocido historietista Caloi publicó cartoons de crítica social en la página final de la revista. Varios de los mencionados eran militantes justicialistas; Contesti en particular había sido diputado nacional hasta el golpe de estado.

Si bien no se trataba de un medio orgánico del Partido Justicialista (PJ), expresión partidaria del peronismo, mostraba afinidad ideológica con su veta ortodoxa, en especial con el sector "verticalista". Este se caracterizaba por defender el liderazgo de la ex presidente Isabel Perón luego de su derrocamiento y cautiverio, tras el golpe de estado del 24 de marzo de 1976, como prenda de la rearticulación partidaria tras la veda política impuesta por la dictadura. Asimismo, contenía en general a los exponentes dirigenciales más intransigentes frente al régimen (Besoky, 2013; Raíces y Borrelli, 2016). Su adversario discursivo primario, en tal sentido, era el sector partidario "antiverticalista", indócil a la ex mandataria y con intenciones de generar cambios en la estructura partidaria. Los "antiverticalistas", en tal sentido, se integraron a las rondas de "diálogo político" promovidas por el régimen y rechazadas por sus adversarios internos, al vislumbrarlas como un espacio propicio ante las

${ }^{1}$ Rosa (1906-1991) integró como historiador la corriente revisionista, crítica de la interpretación denominada "liberal" de la historia argentina y que tendría luego del golpe de estado que en 1955 gran predicamento y sería adoptada por el peronismo como parte de sus componentes doctrinarios. Se desempeñó como embajador en Paraguay y en Grecia entre 1973 y 1976. 
promesas de la sanción de un nuevo estatuto de actividad partidaria (González, 1991). Esta escisión partidaria, por otra parte, provenía de antes de 1976, en plena crisis gubernamental, y se había mantenido tras el golpe. ${ }^{2}$

Para fines de la década del 70, la dictadura había consumado la supresión de la mayor parte de la oposición política, armada y desarmada, y sindical, a través del terrorismo de estado, la censura y la clausura de espacios expresivos. No obstante, enfrentaba un descalabro económico y tampoco lograba consolidar un proyecto político que heredara e institucionalizara su orden de facto, dada las diferencias al interior de la alianza cívicomilitar en el poder y las resistencias de los partidos tradicionales, a la espera de ver restaurada la actividad política suspendida desde 1976. También los medios de comunicación comenzaban a albergar críticas a las políticas económicas y a la situación de los derechos humanos (Novaro y Palermo, 2003; Canelo, 2008; Saborido y Borrelli, 2011). El PJ comenzó desde entonces a asumir un proceso cauteloso de posicionamiento crítico respecto al régimen. Pasará de un tono moderado inicial a un paulatino recrudecimiento discursivo, fundado en el agravamiento de las condiciones socioeconómicas y las restricciones políticas y sindicales al inicio de la década del 80.

En la medida en que los principales partidos opositores comenzaban a articularse -incluido el justicialismo con los "verticalistas"- en torno a lo que, desde 1981 se conocerá como la Multipartidaria, Línea convocará durante 1980-1982 a diversos dirigentes de otros partidos. En sus páginas se pronuncian en reclamo de la recuperación de las instituciones democráticas y la convocatoria a elecciones. 3

Para la revista, los gobiernos justicialistas de 1973-1976 habían sufrido una desestabilización por parte de los "extremismos" de izquierda y derecha como expresión coaligada de intereses

\footnotetext{
${ }^{2}$ La revista consideró a los “antiverticalistas” de oportunistas y “desertores”. Cf. "El papel de los dirigentes". Línea (1980): ${ }^{\circ}$ 7, diciembre, pp. 39-41.

3 Por ejemplo, Línea (1980): año 1, $\mathrm{n}^{\circ}$ 4, septiembre, pp. 36-40. Con la crisis dictatorial, a mediados de 1981 los principales partidos recobran la iniciativa y concretan la formación de una Multipartidaria. Esta entidad aunó a la Unión Cívica Radical, el Partido Justicialista, el Movimiento de Integración y Desarrollo, el Partido Intransigente y la Democracia Cristiana y tuvo como estrategia de mediano plazo negociar con el régimen condiciones para el retorno al estado de derecho y la realización de elecciones.
} 
minoritarios, que dio lugar al golpe militar. 4 Esta interpretación omitía toda referencia a la represión ilegal estatal desplegada desde 1974, que podía relativizar la imagen legalista que pretendía asignarle a tales gestiones. Por su parte, las fuerzas armadas en el poder eran caracterizadas por su conversión facciosa en "partido militar" y su desobediencia a las autoridades constitucionales (Raíces, 2012: 86-89).

Como resultado de su predicamento creciente, Línea sufrió distintas medidas de persecución y hostigamiento desde las esferas oficiales. Entre otras, sufre un allanamiento a su redacción, el secuestro de ejemplares en la ciudad de Buenos Aires y en algunas provincias, así como la veda a su director para efectuar conferencias en la provincia de Córdoba. En sucesivas ediciones, ésta fue dando cuenta de los incidentes referidos a la distribución de sus ejemplares en distintas partes del país. La operatoria oficial tiene como punto destacado el proceso judicial iniciado contra Rosa en julio de 1981, el secuestro del número 10 -analizado en este artículo- y el procesamiento de su director por la Corte Suprema de la Nación, al haber cuestionado un fallo judicial sobre la sentencia referida a la ex presidente Isabel Perón. 5 Como cifra de las repercusiones del caso, referentes políticos de peso, como Deolindo Bittel, el ex presidente Arturo Frondizi, del Movimiento de Integración y Desarrollo (MID), Oscar Alende por el Partido Intransigente (PI) y Néstor Vicente por los demócratas cristianos -no había firmas por la Unión Cívica Radical, el otro gran partido integrante de la Multipartidaria-, deploran la medida judicial y solicitan dejar sin efecto el proceso contra el veterano intelectual revisionista. ${ }^{6}$ Con posterioridad al conflicto de Malvinas, Línea sería clausurada por un breve lapso por decreto de la Junta, durante el cual sus responsables lanzan en diciembre de 1982, la revista Compañero. Esta mantiene el formato gráfico y staff y ofrece contenidos similares a los de la publicación que reemplazaba; sólo aparecería un número, al ser revocada la medida judicial y permitirse la reaparición de Línea (Manson, 2008: 348-354).

4 Seoane Cabral, César:“Perón o la oligarquía”. Línea (1980): n 7, diciembre, pp. 24-28.

5 En agosto del mismo año se conoció el procesamiento de Rosa por haber expresado que la decisión judicial respecto a la ex presidente era "inicua" ("Juicio a nuestro director", Línea, año 2, № 15, octubre de 1981, p. 18; también "¿Por qué me persiguen?”, en Línea (1980): año 2, n ${ }^{\circ}$ 14, septiembre, p. 18). Posteriormente, mediante la remisión a una cita de autoridad como las "Partidas de Alfonso el Sabio", Rosa se referirá de modo indirecto a los jueces de la Corte que habían dado aval al fallo como "pendejos"; ídem: "El sabio y la corte”. Línea (1981): año 2, nº 16, noviembre, p. 11.

${ }^{6}$ Línea (1981): año 2, $\mathrm{n}^{\circ}$ 15, octubre, p. 19. 


\section{En busca de la "cultura nacional"}

La revista cuenta, a lo largo del periodo estudiado, con una sección especializada, denominada "Cultura" -más tarde, "Cultura Nacional”-, de extensión variable pero creciente en términos de las páginas ocupadas con el correr de las ediciones. En contigüidad espacial, pero como veremos también temática, se encuentran las secciones "Juventud", "Medios" y "Reportajes". Entre todas se concentran los artículos de análisis coyuntural relacionados con la cultura, las críticas de libros, algunos aportes literarios eventuales -cuentos, poemas- y reportajes a personalidades sindicadas con el ámbito cultural.

En tal sentido, Línea complementaba su compromiso político con la intención de ocupar lo que detectaba como otra vacancia en la prensa de la época, la de ser la referencia cultural del peronismo. Si bien existía desde 1980 otro medio con la pretensión de reunir la intelectualidad "nacional", la revista Crear en la cultura nacional, gozó de una difusión más acotada (Otal-Landi, 2018). A fines de 1981, Línea publica un texto programático sobre la cuestión. Luego de mencionar la hegemonía de la difusión cultural de signos liberal y marxista, la revista afirma, que

\footnotetext{
"los nacionales aparecen con cuentagotas y la desinformación sobre ellos -pensadores y creadorestiene el público lector, es casi total, llegándose hasta el extremo de desconocerse entre ellos mismos, sobre todo por la falta de una publicación que sirva, incluso, como nexo entre quienes luchan intelectualmente en el mismo frente de lo nacional y lo popular. De aquí y de lo anterior, la necesidad imperiosa de consolidar un canal que sería en estos momentos, el único dedicado a este objetivo estructural de trascendencia” 7
}

Se identifica la autenticidad cultural con la comunidad y se busca bajo el significante de lo "nacional" detectar e interpelar a actores afines, como fin organizador propio de los medios intelectuales (Neiburg, 1998: 59-60). No obstante, algunos colaboradores como Juan Sasturain, según veremos, excedían esa intención y también discutían hacia el campo cultural.

\footnotetext{
7 “El pensamiento nacional”, Línea (1981): año 2, nº 16, noviembre, p. 39. Negritas del original.
} 
En tal sentido, los primeros números de Línea contienen dos artículos que pueden ser leídos como sendas vertientes en que la discusión y análisis cultural de "los nacionales" se disponen en la revista. Por cuanto inauguran el tratamiento del tema mediante formulaciones representativas de los enfoques de la tematización cultural que la revista publicará a posteriori. Se trata de "Acercamiento al tema", de César Seoane Cabral, en el número 1 y “Cultura nacional. Las comunicaciones posibles", de Juan Sasturain, en el 4. El tenor amplio de los títulos, la publicación del primero en la edición inicial y la ubicación del segundo en la doble página central de la revista, refuerzan el tono autoritativo de su argumentación. Estas características les confieren sentido normativo al señalar principios, delimitar adversarios e, implícitamente, sugerir una agenda de intervención cultural en la escena pública.

El artículo de Seoane, como indica su título, pretende por su generalidad inaugurar la sección definiendo sus alcances y, con ello, la concepción en la materia que la revista pretende defender. El autor ensaya una definición de cultura como cualidad de toda "comunidad geohistórica" -asentada en un territorio y poseedora de una historia compartida-, que debe realizarse como estado nacional. ${ }^{8}$ Lo cultural resulta inherente a la existencia comunitaria nacional, por una parte. Por otra, su desarrollo planificado refuerza la conformación comunitaria. Estas nociones esencialistas afirman la existencia de una “cultura nacional” entendida como bloque homogéneo. Evocan, por ello, las formulaciones doctrinarias del peronismo "clásico" de 1946-1955 como ostensible referencia (Fiorucci, 2011). El texto pretende, así, interpelar a aquellos que reivindicaban la existencia de una cultura argentina autóctona, ante la coyuntura de desestructuración social autoritaria y liberalización -económica y, de resultas, de “cambio de mentalidad”, según la afirmación del ministro del área, José Alfredo Martínez de Hoz- que socavaba las bases sociales de identificación peronista, con gesto de recuperación defensiva. Asimismo, se avenía en sus argumentaciones al revisionismo propugnado por la revista, que encontraba también alusiones en constantes referencias en sus páginas a la obra jauretchiana y a la de otros

${ }^{8}$ Seoane Cabral, César: “Acercamiento al tema”. Línea (1980): año 1, nº 1, junio, pp. 26-7. 
autores relacionados -al punto de publicitar en ella el principal sello editorial de esta corriente. 9

Sasturain, pese a presuponer similarmente la noción de "cultura nacional”, la inscribía en un terreno temático y conceptual diferente. Interroga su conformación concreta y el modo en que se jerarquizan sus prácticas y productos, que ejemplifica en torno a los medios masivos. El autor alega que los cánones críticos dominantes deniegan la condición artística de las prácticas y producciones de los creadores en los medios por su inherencia comercial, mientras sostienen la imagen relativamente arcaica del creador "autónomo" exento de condicionamientos mercantiles. Las alusiones a la poética del letrista de tango Homero Expósito y a la tira de humor gráfico de Caloi "Clemente", apuntan a destacar la complejidad y riqueza de los recursos formales puestos en acto, que la orientación al consumo popular o la impronta mercantil del medio y del oficio no desmentirían. Por el contrario, las constricciones estructurales del tango o de la gran prensa resultarían la base de la proyección creativa de ambos. Desmontar la clasificación discriminatoria y las visiones "apocalípticas" de los medios para vitalizar las "comunicaciones" postuladas tiene, acto seguido, una importancia decisiva para una adecuada comprensión y caracterización del cuadro cultural realmente existente. Luego,

"1. Cualquier lectura o historia de los fenómenos que constituyen nuestra cultura nacional ha de partir del cuestionamiento de las categorías que segmentan la producción en obras mayores y menores según los canales utilizados para su difusión: ha de haber una sola plástica, una sola literatura”10

Seoane Cabral parece ampararse en una definición cultural tradicional, donde el componente plebeyo peronista refiere a un "autoctonismo" esencialista. La discusión abierta por Sasturain, por su parte, sin dejar de responder a esa herencia, pertenece a la etapa de

9Del mismo modo, la relación del director de la revista con este editor, Arturo Peña Lillo, titular de los derechos de las obras de Jauretche (1901-1974), y con la viuda del este, permitió que se creara una sección destinada a reproducir fragmentos de libros célebres como el Manual de zonceras argentinas, que devolvían los argumentos revisionistas y nacionalistas populares, esgrimidos en los debates desarrollados entre los años 50 y los 70, a la polémica política actual. Por ejemplo, un trecho crítico de la gran prensa liberal de origen decimonónico, desde el estilo mordaz e irónico que caracterizaba a Jauretche: Ídem: “Ante todo, la fuente”. Línea (1980): año 1, $\mathrm{n}^{\circ}$ 2, julio, p. 23.

10 Sasturain, Juan: “Cultura nacional. Las comunicaciones posibles”. En Línea (1980): año 1, nº 4, septiembre, pp. 24-5. Bastadillas del autor. 
imbricación de las premisas revisionistas con las discusiones apuntadas de los ámbitos académicos y para-académicos sobre la "alta cultura", la cultura popular, las "literaturas marginales" y los alcances e influencias sociales de los medios masivos, en la que participa desde inicios de la década del 70. Su ejercicio ampliatorio del canon cultural, mientras pone en cuestión la concepción hegemónica, incorpora la discusión de la época sobre la potencialidad mediática para expresiones creativas, originales e incluso disonantes con sus imperativos comerciales, la orientación editorial y, también, las intenciones disciplinantes del orden oficial.

Como muestra de su relativa heterodoxia, la siguiente y postrera colaboración de Sasturain en Línea alude inicialmente a una personalidad poco esperable en un medio peronista, la del filósofo francés Jean-Paul Sartre, fallecido pocos meses antes. Lo caracteriza por sus intervenciones intelectuales, mencionando su lucha contra el stalinismo, el neocolonialismo (nombrando al pasar la prohibida obra del intelectual martiniqués Frantz Fanon, Los condenados de la tierra, por su célebre prólogo) y el genocidio vietnamita por los yanquis (sic), para poner su figura en espejo con la propia generación del autor, la de los 70:

\footnotetext{
"Hubo un tiempo en que esa pertenencia al torrente de la historia innegable fue un orgullo, una jactancia, una certeza: hacíamos la historia entre todos (...), ya las opciones no eran filosóficas al estilo Sartre vs. Camus sino tan hermosamente pedestres como Patria o Colonia; Perón sí, otro no y esas cosas dignas de vivir y corear." 11
}

En un medio explícitamente crítico de la movilización juvenil de signo izquierdista (peronista o no) de los 70, como Línea, esta reivindicación afectiva aparece como una audacia, si bien aislada. Por añadidura, para el autor el presente mostraba un panorama en que el protagonismo colectivo de antaño se trastocaba en el quietismo de cada espectador mediático. Del mismo modo, la conversión por los medios de las problemáticas sociales en soluciones de cuidado de sí en términos individuales o el fomento de la preocupación por el destino planetario, "evasivas" en tanto "la salud y la armonía espiritual parecen no tener nada que ver con la justicia, la estúpida y olvidada palabrita que rige o debería regir las relaciones entre los hombres". Crítica política, entonces, de los efectos sociales de la

\footnotetext{
${ }^{11}$ Sasturain, Juan: “Ecología, caspa e historia”.Línea (1980): año 1, nº 5, octubre, pp. 22-23.
} 
represión, de las innovaciones aparentes que la nueva sociedad "abierta" por la liberalización mercantil de facto había recibido, y de la complicidad mediática por "escamotear la realidad" (sic). ${ }^{12} \mathrm{Su}$ contrapunto conclusivo sería el llamado indirecto a recuperar el sentido de la acción política ("nacional”). En este último plano, no en el de sus referencias setentistas, Sasturain converge con la revista.

Posteriores contribuciones de otros autores, con similares intenciones totalizadoras y programáticas del panorama cultural, pueden rastrearse en las postrimerías de la periodización propuesta. Es el caso de un artículo firmado por Luis Barroso y publicado a principios de 1982. ${ }^{13}$ Para entonces, la inestabilidad de la Junta militar y el acrecimiento de la oposición política, social y sindical había radicalizado el tenor opositor de la revista. Este texto confronta declaraciones polémicas del novelista peruano Mario Vargas Llosa contra lo que llama "nacionalismo cultural", vertidas durante su visita a la Feria del Libro. ${ }^{14}$ Erige su concepción liberal, abierta y cosmopolita, de la producción e intercambio de los bienes culturales, contra la idea de su definición en términos nacionales. Barroso califica esta postura como propia de "mentes colonizadas" y reivindica la defensa de los "hábitos de vida" populares, que entrevé puestos en cuestión por los medios de comunicación en manos foráneas (y explicitando lo que en Seoane se podía deducir por contraste). Pero también efectúa un juicio de los cinco años de dictadura transcurridos, no necesariamente limitable al plano cultural:

“¿Sabrá Vargas Llosa lo que significó en este país más de cinco años de Proceso? ¿Tendrá presente lo que son la censura, la persecución, el exilio, la destrucción del patrimonio nacional? ¿O él también creerá que lo del genocidio cultural en nuestro país es puro verso?”

El autor destaca de esta forma el término "genocidio cultural", acuñado desde el exilio por el escritor Julio Cortázar. Este gesto demuestra la difusión relativa de la polémica entablada

${ }_{12}^{12}$ Donde el "escamoteo" mediático se combina con el mencionado "quietismo" de la audiencia. Esta parece una concesión al juicio "apocalíptico", pesimista, de otros autores, en un crítico que adscribe por formación e influencias a una valoración más matizada del influjo mediático, en consonancia con las posiciones por la misma época de otros intelectuales orientados al análisis mediático como Heriberto Muraro y Aníbal Ford -ideológicamente cercanos a Sasturain-.

${ }_{13}$ Barroso, Luis: “Cultura: ¿emancipación o dependencia? Una respuesta a Mario Vargas Llosa sobre la cultura”. Línea (1982): año $3, n^{\circ} 20$, marzo, p. 30 .

14 Publicadas en suplemento “Clarín Cultura y Nación”. Clarín (1982), 18 de febrero, p. 1. 
al respecto entre escritores residentes y exiliados (Jensen, 2005). Del mismo modo, su destaque en negritas y una alusión posterior en el texto a las desapariciones indica un clima de época que facilita comenzar a referir -y a discutir los modos de hacerlo- de manera abierta, directa, las consecuencias de la represión dictatorial.

Lejos de las problematizaciones teóricas, no obstante, la relación entre política y cultura se vuelve a postular bajo el condicionamiento del segundo término por el primero:

"La nota [con las declaraciones de Vargas Llosa] aparece en un momento justo, en que diversos eventos (Teatro Abierto, Musicasiempre, Festival de rock de La Falda, declaraciones de intelectuales, etc.) permiten inferir que, en consonancia con el pueblo todo, la cultura argentina se prepara para una contraofensiva que restablecerá los verdaderos términos de la democracia, tan necesaria por estos lados para hablar no sólo de política cultural". 15

Con excepción posible de las declaraciones indeterminadas, las actividades que se mencionan coinciden en no articularse por referencias políticas. Mientras en ciertos casos (el caso del movimiento Teatro Abierto, por ejemplo) generan declaraciones o manifiestos que asocian su desarrollo con la defensa de la "cultura argentina" frente a las restricciones a la libertad de expresión y la situación económica, tampoco pueden ser relacionadas en sentido estricto con una postura nacionalista cultural. Desde esta última perspectiva, se las emplaza como ejemplos de una autenticidad cultural e intelectual frente a lo otro inauténtico oficial. Como tales, se les asigna un rol fundamental en el retorno al régimen democrático junto (con el empleo del término "contraofensiva", de resonancia por entonces reciente por las trágicas acciones de la organización Montoneros ${ }^{16}$ ).

\footnotetext{
15 Ibídem. Negritas del original. Aparte de los eventos ya mencionados en esta tesis, el Festival de rock de La Falda, se llevó adelante en la provincia de Córdoba entre 1979 y 1987.

${ }^{16}$ Por "contraofensiva" se conoce la operación desarrollada entre 1979 y 1980 por la organización revolucionaria Montoneros para aprovechar la crisis de la dictadura y socavar sus bases sociales de sustentación. Implicó el retorno de militantes exiliados para desarrollar acciones de propaganda y de orden militar. Fue desbaratada por las fuerzas armadas y gran parte de los arribados fueron asesinados o desaparecidos.
} 


\section{La crítica cultural}

Para el número 10, se publica un informe especial de reseña de los cinco años transcurridos del gobierno militar, presentado en portada bajo el nombre "La Argentina secreta" (Imagen 1) y con un apartado para la actividad cultural. La denominación responde a una metáfora atribuida a declaraciones de monseñor Zazpe, citado en el marco del informe, y replica la metáfora de las “dos argentinas”. Su gráfica de tapa busca representar esa caracterización, personificándola: el país asume la figura de un rostro fotografiado en primer plano, amordazado y cegado con una venda negra. Como escena emblemática, admite dos lecturas posibles y complementarias: una situación de incomunicación forzada que pretende metaforizar la falta de libertad de expresión y la censura. En segundo lugar y para aquellos que pudieran reconstruir los indicios ofrecidos, corporiza adicionalmente una situación de detención ilegal asociada al secuestro de personas, relacionable con la actuación clandestina del terrorismo de estado.

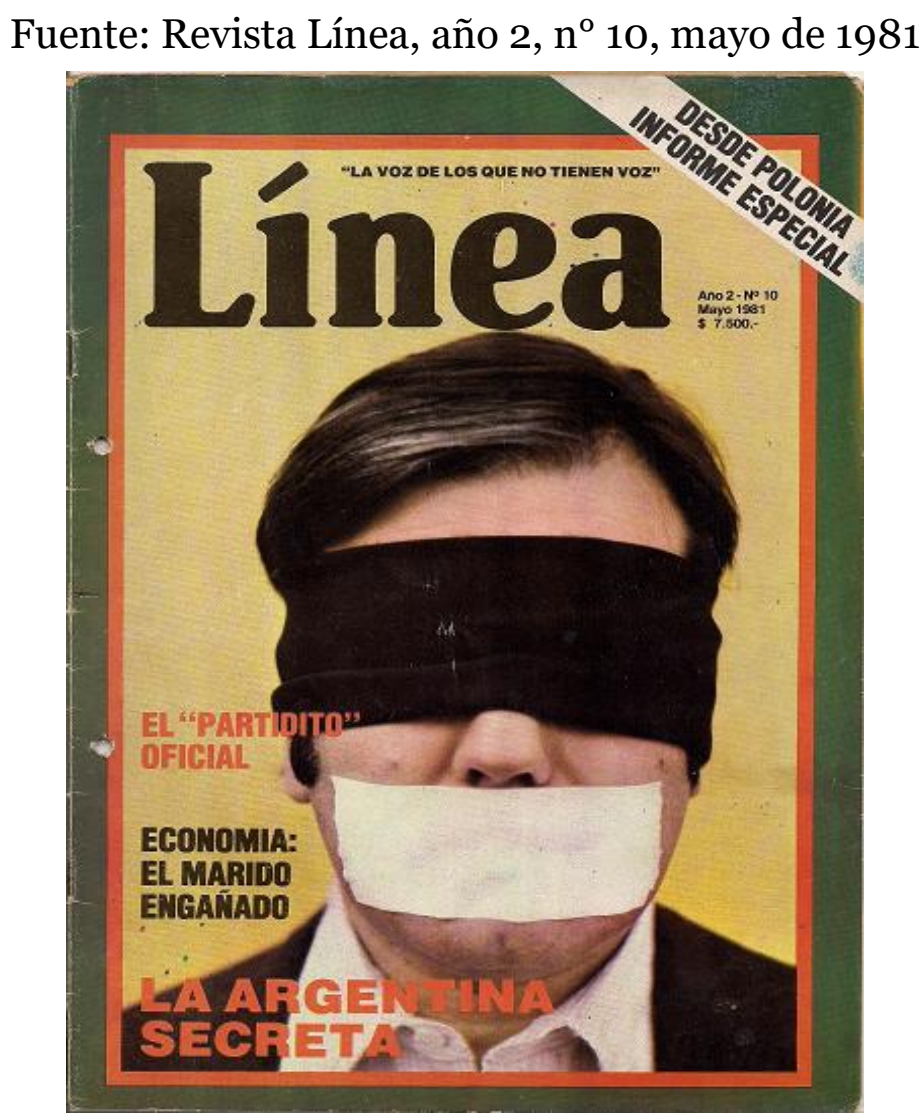

Imagen 1. Portada de Revista Línea, año 2, $n^{\circ}$ 10, mayo de 1981. "La Argentina secreta". 
La edición obtuvo la repercusión pretendida, al punto de terminar siendo confiscada por las autoridades. En el número siguiente se denuncia el suceso y se informa que la edición fue posteriormente devuelta, pero que se impidió su circulación en varias provincias. ${ }^{17}$

El informe ocupa las páginas centrales y ostenta el nombre de "Radiografía de la Argentina secreta", cuyo primer término lo identifica con la corriente literaria del ensayo de interpretación nacional de los años 30. Para los lectores que saben leer tales indicios, la referencia permitiría, además, hallar semejanzas entre la crisis de la dictadura con la experimentada durante la "década infame”. Crisis que, según se enuncia en la presentación del informe, "se paga no sólo en valores económicos, sino culturales y también de voluntad nacional”. ${ }^{18}$

Por su condición de nota de tapa, editorializa y, en particular, permite circunscribir la forma en que delimita y analiza desde esa perspectiva -ya no "de opinión" al modo de las contribuciones individuales firmadas- los contenidos asignados a lo cultural dentro de esta mirada de conjunto sobre la situación social del país. ${ }^{19}$ La "Radiografía cultural" consta de una doble página, ilustrada con una fotografía del cineasta y cantante Leonardo Favio, icónico por su identificación como realizador cinematográfico, cantante melódico popular y a la vez como militante peronista. ${ }^{20} \mathrm{El}$ texto parte de la noción revisionista-peronista de cultura como sustancia popular, con los temas de la autenticidad y la alienación. Desde esta perspectiva, la clave de la crisis en su aspecto cultural radicaría en que en el periodo de facto

“al pueblo argentino se lo descentró de su realidad (...). La valorización de lo exterior, la desconexión con la propia realidad y necesidad y el miedo - esto es la censura- fueron configurando e incidiendo, lógicamente en la producción cultural de toda nuestra sociedad.”21

${ }^{17 L i ́ n e a ~(1981): ~ a n ̃ o ~ 2, ~}{ }^{\circ}$ 11, junio, p. 2. La portada de este número inmediatamente posterior, en blanco y con la sola leyenda "Tapa aprobada por la censura", apuntó a redoblar la apuesta ante los censores oficiales.

${ }^{18}$ Línea (1981): año 2, ${ }^{\circ}$ 10, mayo, p. 18.

${ }^{19}$ Según consigna la introducción, la redacción del apartado económico fue responsabilidad de Osvaldo Granados, del político de Rodolfo Audi, una interpretación histórica fue encarada por Marino Faliero y testimonios de trabajadores fueron tomados por Luis Gramuglia. Ibídem, pp. 18-27 (p. 18: información sobre realizadores del informe).

${ }^{20}$ No se menciona autoría para la sección “cultural”. Oscar Raúl Cardoso se encargó de editar el conjunto del material.

${ }^{21}$ Ibídem. 
El segundo aspecto sustantivo de la "Radiografía" lo constituye el establecimiento de las materias del continente cultural; para ello, el informe se organiza en siete categorías: cine, televisión, plástica, literatura, danza, música y teatro. El rango de las producciones simbólicas mencionadas ratifica una visualización convencional de la cultura, matizada por la incorporación de la industria audiovisual -de fuerte desarrollo durante el peronismo “clásico"-, al tiempo que el tratamiento de cada ítem permite observar cómo Línea aplica, de manera sumaria, los parámetros crítico-clasificatorios "nacionales" al desbrozar lo valioso de lo insignificante en la materia.

En el apartado sobre el cine, calificado de "el instrumento de producción de cultura más importante y masivo", se contraponen de modo ejemplar los filmes "Historia del Aniceto y la Francisca", de Leonardo Favio y "La Patagonia rebelde", de Héctor Olivera, a lo que se califica como banalidad y escasa profundidad temática de la mayoría de las películas estrenadas. Lo que aquellas poseerían de apego a una estética inmanente y a la recreación histórica realista-social estaría ausente en los filmes contemporáneos, con la excepción de los de Sergio Renán y de Mario Sábato, ponderados por su búsqueda de un lenguaje cotidiano y un color local urbano, pero aislados en su intento. ${ }^{22}$ El énfasis es puesto, por ello, en una representación bajo la pretensión (revisionista) de la aportación del arte a develar lo existente.

En lo atinente al medio televisivo, se hace foco en el fenómeno de las telenovelas. Para Línea, ellas componen el paradigma del escapismo del medio, en tanto

\footnotetext{
${ }^{22}$ La denominación completa del filme de Favio es "Éste es el romance del Aniceto y la Francisca, de cómo quedó trunco, comenzó la tristeza y unas pocas cosas más...” y fue estrenado en 1966; los títulos producidos por Sergio Renán durante la dictadura fueron "Crecer de golpe" (1976), en base a una novela de Haroldo Conti, detenido-desaparecido el mismo año; "La fiesta de todos" (1978), celebratoria del mundial 78, y "Sentimental” (1980), sobre una obra de Geno Díaz. Por su parte, Mario Sábato produjo dos largometrajes de la saga de los parapoliciales "superagentes": "Los superagentes biónicos” (1977), "Los superagentes y el tesoro maldito" (1978). Posteriormente, dirigió un drama basado en un capítulo de Sobre héroes y tumbas, de Ernesto Sábato, "El poder de las tinieblas" (1979) y una comedia dramática, "Tiro al aire" (1980), además de tres títulos sobre el conjunto musical español Los Parchís y una tercera secuela de los "superagentes".
} 
"llenaron de información vacía, falsas vidas y falsos problemas, las vidas llenas de problemas reales que no podían resolver ni discutir, de muchos televidentes a quienes le resulta menos pesado lamentarse de las desventuras de los personajes que enfrentar las propias". 23

Lejos de cualquier matización, la sublimación aparente de los problemas sociales en la ficción televisiva es tomada como paradigma del carácter manipulatorio que la revista asigna con frecuencia, según veremos, a los medios de comunicación en dictadura.

Similar criterio ("realismo/evasión") se mantiene sobre la plástica, al calificarla globalmente por su tendencia a una "descontextualización" fomentada por la censura y el discurso moralizador oficial. Por su parte, el apartado dedicado a la literatura deplora la falta de ensayos de interpretación nacional -género estrella del revisionismo (Saitta, 2004)- y la banalización temática de la novelística, mientras advierte por contraste la escasa difusión del libro de cuentos Dublín al Sur, escrito por Isidoro Blaisten. Narrador de situaciones y escenarios urbanos, Blaisten mezcla en sus tramas el realismo y lo fantástico con un humor ácido. Pese al reclamo de Línea, el mismo año de su publicación había obtenido el Primer Premio Nacional de Literatura, una de las formas clave de consagración crítica y de acceso a la industria editorial. 24 Por otra parte, y frente al decaimiento de la literatura con circulación comercial (De Diego, 2003: 97-98), la revista ensalza la creciente repercusión en la prensa gráfica de las revistas "alternativas” y "subterráneas" -será tratada en el siguiente capítulo-.

Con respecto a la danza, se la define por su situación permanentemente marginal ante un panorama dificultoso para montar espectáculos y acceder al circuito teatrístico oficial por parte de las puestas experimentales. El juicio sobre el campo musical abarca la música "culta” y el rock. Para la primera, se destaca la aparición de jóvenes talentos, aunque se señalan similares impedimentos a los de la danza. Para el segundo, se pondera la reciente apertura de pequeños locales y se lo parangona con “otras formas musicales”, ejemplificadas por la mención de los músicos Charly García, Rodolfo Mederos, Luis Alberto Spinetta y Rubén Rada. El que estos artistas diversos fueran agrupados, además de resaltar la

${ }^{23}$ Línea (1981): año 2, $\mathrm{n}^{\circ}$ 10, mayo, p. 26.

24 La primera edición de Dublín al sur fue lanzada en 1979 y obtuvo ese mismo año el Premio Nacional de Literatura. Exactamente un año después del informe, durante la guerra de Malvinas, Blaistein es reporteado por la revista. Ver Línea (1982): año $3, \mathrm{n}^{\circ}$ 22, mayo, pp. 26-7. 
consciencia del grado de fusión musical que emprendían, permite ante todo resaltar la significación social del rock como movimiento. 25

Una lectura de conjunto del Informe permite observar que los análisis tienden a favorecer no sólo una lectura realista social, sino también la acepción tradicional de la actividad cultural, con la usual connotación esencializada:

"La cultura no se consume, decíamos, se produce. La produce el pueblo día a día con la relectura que hace de aquello que los hacedores de cultura le ofrecen. La realizan los músicos, los poetas, los hombres de teatro y cine cuando pueden espejar y transformar en símbolo, sin miedo a aquello que van viendo y sintiendo en su entorno." 26

También la empresa crítico cultural de Línea incluye reportajes a distintos actores relacionados con el rango cultural pregonado, de acuerdo a su búsqueda de fortalecerse como núcleo intelectual del "campo nacional". Para ello, reportea a algunas figuras con repercusión en el espacio mediático, con predominio de la prensa gráfica, el cine, el teatro y el medio televisivo, junto a algunos exponentes de la cultura letrada. ${ }^{27}$ En sus introducciones, la revista destaca entre otros aspectos el carácter popular, la condición representativa de lo "nacional", el tenor testimonial/realista de la obra y el compromiso de

${ }_{25}$ Con respecto a las fusiones, pueden consignarse el jazz y el tango desde el rock (Spinetta), el jazz y el rock desde el tango (Mederos), el sinfonismo, el jazz y también el tango desde el rock (García) o la combinación de jazz y rock y candombe (Rada). Como referencia, considerar los siguientes álbumes musicales, según el orden de los nombrados: "Alma de Diamante”, Ratón Finta, 1980; “Todo hoy”, AURIS, 1978; "Bicicleta”, SG Discos, 1980 y "La Banda”, Sazam Records, 1980, alrededor del periodo considerado.

26 "Radiografía cultural”, Línea (1981): año 2, n 10, mayo, p. 27.

${ }_{27}$ Por orden cronológico: al dramaturgo Humberto Rivas, Línea (1981): año 1, nº 8, marzo, pp. 24-5; al historietista Caloi (Carlos Loiseau), Línea (1981): año 2, nº 9, abril, pp. 34-35; al pintor Vicente Forte, Línea (1981): año 2, nº 10, junio, pp. 3435 (póstumo y con autoría de Pablo Hernández); a los teatristas Néstor Zapata (grupo Arteón de Santa Fe), R. Santillán (teatro de "Los siete", Córdoba) y Ricardo Talento (Taller de Cultura Nacional, Capital Federal), Línea (1981): año 2, nº 12, julio, pp. 44-45; al músico de tango Osvaldo Piro, Línea (1981): año 2, n ${ }^{\circ}$, agosto, pp. 40-1; al director cinematográfico Lucas Demare, Línea (1981): año 2, $\mathrm{n}^{\circ}$ 14, septiembre, pp. 40-41; al novelistaDalmiro Sáenz, Línea (1981): año 2, n 15, octubre, pp. 38-9; a la actriz Haydeé Padilla, Línea (1981): año 2, n 16, noviembre, pp. 36-8; al escritor Enrique Medina, Línea (1982): año 3, nº 19, febrero, pp. 28-29; al cantor de tango, actor y director cinematográfico Hugo Del Carril (firmada por Pablo Hernández), Línea (1982): año 3, nº 20, marzo, pp. 26-7; al escritor Isidoro Blaistein, Línea (1982): año 3, nº 22, mayo, pp. 26-7. Incluimos a este último por su tratamiento crítico previo por parte de la revista, si bien por su fecha este reportaje quedaría levemente por fuera de la periodización propuesta. 
cada actor cultural con su entorno, como criterios de selección. ${ }^{28}$ En la nómina conviven aquellos con una adscripción peronista reconocida y plena actividad como Caloi, Humberto Rivas y Dalmiro Sáenz, junto otros identificados con los primeros gobiernos justicialistas (1946-1955) y ya en etapa declinante, como Hugo Del Carril. Incluso es entrevistado un otrora destacado cineasta como Lucas Demare, ponderado por su perspectiva realista, pero que una mirada retrospectiva trabajosamente podía asociar al peronismo (Piedras, 2005: 85-97). ${ }^{29}$ Casi sin excepción, los testimoniantes evocan en los reportajes dificultades para su ejercicio profesional, centrados en la situación económica, las constricciones censorias y la existencia de listas negras en el caso de los medios. Definen como parte integrante de la labor artística la insumisión al poder:

\begin{abstract}
"Yo siento mucho nuestro paisaje, nuestra tierra, y he hecho también muchas películas de denuncia. Aunque no soy quien, pero creo que es importante hacerlo porque no doy soluciones, pero se ayuda a pensar a quien tiene que dar esas soluciones"
\end{abstract}

"En el mundo perfecto no existirían escritores, pues la pluma del escritor se nutre de la injusticia y de la queja. Es un anticuerpo."30

Estos nombres posibles de una cultura peronista acompañan, así, el discurso crítico de la revista. Incluso aquellos que, sin reconocerse o estar connotados de tal modo, satisfacen los criterios arriba mencionados y son enmarcables en el amplio arco significante de los

\footnotetext{
${ }_{28}$ Para el caso de los escritores, se presenta a Dalmiro Sáenz como un literato "totalmente jugado por la causa única que debe jugar un intelectual: la causa de su pueblo"; y a Enrique Medina por producir una "literatura comprometida, dolorosa". Cf. textuales en reportajes a ambos, ibídem. Ver también los postulados de la revista, ya citados, en "Radiografía cultural", Línea (1981): año 2, nº 10, mayo, p. 18.

${ }_{29}$ Sobre la convocatoria de la revista a los intelectuales "nacionales", "El pensamiento nacional”, Línea (1981): año 2, no 16, noviembre, p. 39. Demare, definido por Línea como "uno de los más grandes directores-productores del cine nacional” y fallecido al poco tiempo del reportaje, resultaba afín a las intenciones de la revista, por profesar en su obra el costumbrismo y la denuncia social, satisfacer el criterio realista y manifestarse crítico de la censura y del comercialismo de las propuestas cinematográficas existentes. Si bien fue prolífico durante 1946-1955, luego del golpe de estado Demare había consumado junto al guionista Sixto Pondal Ríos el film "Después del silencio" (1956), que ficcionalizaba la supuesta opresión del régimen justicialista derrocado (ya su título resultaba ilustrativo de las intenciones de los realizadores). También "Detrás de un largo muro" (1958), otra película del dúo, toca más veladamente la etapa peronista a través de una historia de migración del campo a las villas de emergencia (luego, denominadas "villas miseria").

$3^{30}$ Reportajes a Lucas Demare, Línea (1981): año 2, $\mathrm{n}^{\circ}$ 14, septiembre, p. 41; a Dalmiro Sáenz, Línea (1981): año 2, n ${ }^{\circ}$ 15, octubre de 1981, p. 39, respectivamente.
} 
"nacionales" -al punto que Blaisten, ya mencionado, agradece su convocatoria pese a no ser peronista y, de resultas, explicita la estrategia de "apertura" de la revista-. ${ }^{1}$

\section{Los medios en dictadura como empresa cultural antinacional}

Para Línea, asimismo, la cuestión cultural aparece constantemente relacionada con los medios de comunicación. Esa relación patentiza, sobre todo, las tensiones con que la revista aborda el campo cultural. Si los medios son la condición de la difusión moderna de los contenidos culturales a las mayorías populares, también supondrían una amenaza permanente para su esclarecimiento por la "comercialización de la cultura" supuesta en su accionar, que la dictadura en su labor extranjerizante habría potenciado.

Lo antedicho se advierte contemplando sus análisis del sistema mediático argentino con especial atención a los audiovisuales, a los que se asigna una influencia destacable. Esta perspectiva encuentra expresión a través de una serie de notas sobre los alcances y finalidades del medio televisivo. Su autor, Pedro García, a la par de concederle decisiva influencia social, que apuntaría a moldear "la estructura del mundo actual", expresa su intención de introducir "una discusión reflexiva y crítica" sobre la tv. ${ }^{32}$ Apunta a demostrar que la programación de bajo nivel y la censura imperante en los formatos noticiosos tienen como meta “formar un espectador 'modelo' que 'absorba' y 'reciba' mensajes previamente descifrados y que pierda diariamente su capacidad de análisis" 33 En las notas siguientes, desarrolla los puntos mencionados con mayor detenimiento, a partir de la posible privatización de canales y radios $\left(\mathrm{n}^{\circ} 2\right)$, la autocensura oportunista de algunas figuras del medio ( $\mathrm{n}^{\circ}$ 3), la crítica de una programación que entrevé elaborada e implementada para desinformar a su audiencia $\left(n^{\circ} 4\right)$ y la publicidad como recurso experto para potenciar el consumismo $\left(\mathrm{n}^{\circ} 5\right)$. En dichos estudios, con fuerte interés en el público potencial de las emisiones mediáticas, subyace una mirada que concede a estas gran poder de persuasión, en especial ante lo que se entrevé como "manipulación publicitaria” en la conductas de la

\footnotetext{
${ }^{31}$ También el novelista Enrique Medina guarda en su reportaje distancia de las identificaciones políticas y defiende el rol de la literatura como medio de incomodar al poder, satisfaciendo el criterio realista apuntado. Ver Línea (1982): año 3, $\mathrm{n}^{\circ} 19$, febrero, p. 28.

$3^{2}$ García, Pedro: “TV: 'Los únicos privilegiados son los otros”, p. 28. Línea (1980): n 1, junio, pp. 28-30.

33 Ibídem, p. 29.
} 
audiencia.34 Al respecto, estas referencias a la alienación del espectador con estilo crítico moralizante (es decir, político para Línea) se mixturancon intentos descriptivos que hacen a la economía política del sistema mediático.

Este perfil interpretativo, que hace de los medios una punta de lanza de la "reforma intelectual y moral" operada por la dictadura para introducir un modelo de ciudadanía liberalizada, individualista y consumista - contrario al perfil ciudadano "comunitarista" promovido por Línea con base en la doctrina peronista-, convive sin estridencias con la defensa por Sasturain de los medios como espacios que desde su estructuración comercial admiten la existencia de producciones artísticamente valiosas.

\section{La "nueva sensibilidad" juvenil como horizonte}

Pero también ínea extiende su atención a prácticas culturales relacionadas con los sectores juveniles y no reconocidas en el canon cultural consagrado, de acuerdo con la clasificación sasturaniana. Se trata de un reconocimiento al valor artístico específico del rock y de las revistas "subte", por añadidura de experiencias juveniles urbanas relacionadas con las capas medias y de su potencia emergente y movimientista. Por lo mismo, de un sujeto (juvenil) ajeno a la impronta obrerista y plebeya asociada al peronismo que la revista asume.35 Tal aprecio entraña un carácter analítico específico, a la vez que instrumental. Línea explicita, al respecto, la finalidad intrínseca al proyecto editorial de atraer a las capas juveniles al "movimiento nacional". Desde su comienzo se propone la interpelación de sus intereses sociales y políticos; el primer número incluye la sección "Juventud”, donde apunta a caracterizar el modo en que se las percibe:

“Con la excusa de que 'no vuelva a equivocarse' se procede a una verdadera proscripción de los jóvenes por el hecho de serlo, un clima de desconfianza alimentado cotidianamente que conduce a una

34 García, Pedro: “La irrealidad es la única verdad”, p. 29. Línea (1980): año 1, nº 5, octubre, p. 29.

$35 \mathrm{Al}$ describir el público lector presunto de la novela best seller Flores robadas en los jardines de Quilmes, a la que nos referimos a continuación, como una "generación intermedia intelectual", la revista admite explícitamente que esta -y no necesariamente un lectorado obrero- ha de componer igualmente su público. Cf. "Flores robadas de los jardines de Quilmes" p. 44. En Línea (1981): año 2, nº 8, marzo, pp. 44-45. 
disyuntiva maniquea: el interés por lo social y lo político es malo, cualquier otra cosa (cualquiera sea la 'otra cosa') es bueno." 36

Un caso resonante como el de la exitosa novela Flores robadas en los jardines de Quilmes, de Jorge Asís, que evoca de modo pionero y desde la ficción el derrotero de la generación de los 70, del compromiso y la militancia política a la represión, le permite no sólo censurar el extravío juvenil guerrillero -que había desestabilizado los gobiernos justicialistas de 19731976 y dado motivos para el golpe militar, según la revista- y justificar sus intenciones de canalizar las energías de la renovada generación hacia la recuperación democrática, en términos institucionales y desde el sesgo no "internacionalista" sino "nacional".37

Así, la revista por una parte irá convocando a las juventudes partidarias en función de su afinidad en el marco de la Multipartidaria: dirigentes de las agrupaciones universitarias Franja Morada (cercana a la UCR), Juventud Universitaria Nacional (al PJ) y Movimiento Nacional Reformista (afín al Partido Socialista Popular) son consultados sobre la situación institucional. ${ }^{8}$ También desde sus páginas invita a los jóvenes a acercarse para recibir formación doctrinaria "nacional”. 39

Por otra parte, secciones específicas de cultura y de juventud concentran el abordaje de distintos fenómenos relacionados con la cultura juvenil, fundamentalmente el rock que desde el punto de vista del "pensamiento nacional" había sido sindicado durante la década anterior de "extranjerizante" (Pujol, 2007b: 312-313; Alabarces, Añón y Conde, 2008: 268). Al mismo tiempo, se realizan varias menciones y artículos sobre las revistas alternativas y "subte" durante 1981. Y se convoca a testimoniar a participantes de ambas experiencias, en tanto que jóvenes activistas culturales.

\footnotetext{
36 "La despolitización por la idiotización”, p. 43. En Línea (1980): n 1, junio, pp. 43-44.

37 "Flores robadas de los jardines de Quilmes", p. 44. Línea (1981): año 2, nº 8, marzo, pp. 44-45.

${ }^{38}$ Las agrupaciones son convocadas a un encuentro organizado por Línea. Ver Línea (1981): $\mathrm{n}^{\circ}$ 11, junio, pp. 40-41 (artículo "Universidad y participación política”) y 42-43 (declaraciones, “Opiniones desde el aula”). En el número 13 de agosto vuelve a convocarse una mesa redonda de "juventudes políticas".

39 “La respuesta juvenil”, Línea (1981): n 14, septiembre, p. 36.
} 
En consecuencia, conviven en la revista dos abordajes diferentes sobre el sujeto social juvenil. En primer lugar, el concentrado en la juventud como sujeto a interpelar, formar y organizar para el "campo nacional”. En segundo lugar, el que interroga las prácticas simbólicas que definen su identidad e intenta caracterizarla mediante análisis y dándole voz a través de testimonios, con intención convergente con el anterior.

Dos colaboradores aportan las contribuciones fundamentales, Rosa Ferrer y Luis Barroso, a la vez que aparecen algunas sueltas anónimas. Inicialmente el artículo no firmado "Rock y política”, que inaugura la sección "Juventud” en el número 9, presenta desde el título las vinculaciones ulteriores que propondría la revista respecto a la cuestión juvenil. No obstante, los define en términos generacionales bajo el presupuesto de que la actual ostenta formas de percibir, de apreciar, clasificar y distinguir diferentes de las anteriores. 40 Constata la afluencia de público a recitales para preguntarse por las razones del fenómeno e indagar las características de la música ofrecida, en tanto los reconoce como su espacio excluyente de convocatoria masiva, donde pueden "en conjunto elegirse y ser de determinada manera". Los vislumbra como "espacios libres" sustraídos de la tensión, represión y autocensura societal general, en un marco en que se habían multiplicado los espacios expresivos de la "música joven" (Pujol, 2007a: 171 y ss.). ${ }^{41}$ En lo musical, destaca las letras que les permiten "reconocerse", una rítmica acorde al pulso del trajín urbano y también las tentativas de incorporación al rock de otros géneros, ejemplificados en el texto por la obras de León Gieco y del uruguayo Rubén Rada, a los que se suma a los brasileros Milton Nascimento, Caetano Veloso y Chico Buarque, por influjo para entonces de sus recientes y exitosas presentaciones. Lejos de toda suspicacia, el rock cobra aquí una imagen positiva, abierta a la combinación con otras músicas, inclusive extranjeras, con arraigo metropolitano, y resalta como acontecimiento juvenil por excelencia:

\footnotetext{
40 "Rock y política”, Línea (1981): año 2, nº 9, abril, pp. 38-39. Asumimos que este artículo es de autoría de Rosa Ferrer, al anunciar el texto uno próximo sobre el contenido y corrientes del rock nacional y de la música popular brasilera, publicado en el número siguiente con su firma, y ostentar un estilo de escritura similar entre ambas contribuciones. Sobre el concepto de "generación".

${ }^{41}$ Una coincidente apreciación sobre la apertura de espacios para el rock en "Radiografía cultural”, p. 27. Línea, (1981): año 2, $\mathrm{n}^{\circ}$ 10, mayo, pp. 26-7.
} 
"Lo importante de este fenómeno es una sensibilidad masiva (...). Aquí tenemos fenómenos masivos que, más allá de que hayan sido estimulados por los intereses económicos que los auspician, encuentran un público que los conforma." 42

El empleo del término "sensibilidad" y, previamente en el texto, "nueva sensibilidad" connota, en función de lo antedicho, la intención de pensar la nueva generación por la adscripción de sus propias estructuras de sentido y, con ello, formas diferenciadas de las precedentes de percibir y de apreciar el mundo social que en cierto modo portan un cambio cultural (Margulis y Urresti, 2000: 18-19). Amén de evocar, de modo reminiscente y en términos históricos, a las vanguardias artísticas argentinas (Vázquez, 2000: 60). 43 El caso indicador del artículo parangona la escucha atenta de los asistentes ante la transición del grupo rockero Serú Giran de la electricidad al reposado momento solista de su integrante Pedro Aznar, con el efecto de la poética tanguera de Homero Manzi y de los hermanos Expósito (pero en esta, para el crítico, sin una recepción masiva). Lo que distinguiría esta sociabilidad situada es la conjunción entre una creación refinada y una valoración acorde de la audiencia, no sólo dispuesta a la rítmica del baile sino a una escucha atenta, que confirma que estas manifestaciones musicales siguen "la rítmica del acontecer histórico".44 La estética entrañaría una ética colectiva en acto frente al hecho musical. "Ser y elegirse" expresa la manifestación de una libertad contrastante con la opresión extramuros, donde se combinan el disfrute y cierta toma de consciencia. En otros términos, la sensibilidad proclamada supone una forma espontánea de coincidencia juvenil y de rechazo del consumismo, de los modelos juveniles oficiales "blancos" (ver Pujol, 2007a) y de los "líderes sicopáticos" (sic) que refieren a la generación militante izquierdista de los 70-. Esta forma de definir el colectivo juvenil aparece relacionada, por ello, con su potencial anticipatorio de cambios sociales trascendentes que rebasa el aspecto comercial del momento del espectáculo, y marca este aspecto como factor indicativo de su disponibilidad política. Se impone, entonces, crear espacios "para que [estos jóvenes] puedan integrarse al movimiento nacional, con el ritmo, la medida y la armonía que ellos decidan” (mezclándose rítmica y

42 "Rock y política”, p. 38. Línea (1981): año 2, nº 9, abril, pp. 38-39.

43. "Nueva sensibilidad" constituye el subtítulo del apartado del texto a que corresponde la cita y se ajusta a la noción propuesta por el filósofo español José Ortega y Gasset en sus conferencias de Buenos Aires en 1916; posteriormente es adoptado por el movimiento literario organizado alrededor de la revista Martín Fierro.

44 “Rock y política”, p. 38. Línea (1981): año 2, nº 9, abril, pp. 38-39. 
armonías musicales con la célebre frase peroniana de "todo en su medida y armoniosamente" como rasgo humorístico que denota el optimismo del autor). En suma, la sociabilidad que entraña la "nueva sensibilidad" como tendencia cultural detectable, podría conducir a la organización política de esos sectores. 45

Otro artículo posterior, firmado por Ferrer, concibe al arte como objeto de un compromiso específico, no político, pero generador de mensajes no fácilmente controlables para el poder, con destinatarios receptivos. Subyace en este análisis la percepción de que esta vinculación entre artistas y público compensaba en parte otras prácticas sociales vedadas (Alabarces, 1993: 73-74). Por su parte, Luis Barroso aborda la "nacionalización" del rock, estableciendo una trayectoria de grupos que componen en castellano y arranca en los años 60. Para el autor, juventud y rock van de la mano, y reconocer tal relación resulta indispensable para una tarea política que ocupa un ámbito diferenciado:

"La música es el código actual que permite a la juventud, la comunicación más inmediata, y precisamente en ese terreno se produce ese fenómeno llamado rock. Generadora de fervorosas adhesiones y repulsas, la música rock se fue transformando en un lenguaje cuya ignorancia implica el desconocimiento de una época y la imposibilidad de comunicarse positivamente." 46

Pero la "nueva sensibilidad" aparece desplegada igualmente en el movimiento editorial juvenil de las revistas autogestionadas o "subte" (Margiolakis, 2014; 2016). En el ya citado informe "Radiografía de la Argentina secreta", su acápite cultural dedica la mitad del apartado de literatura a destacar estos medios de quienes

\footnotetext{
45 "Estos muchachos están tempranamente preparados para una introducción en la política, con mayúscula, exactamente igual que otros jóvenes que están tempranamente introducidos en el duro mundo del trabajo". "Rock y política”, p. 39. En Línea (1981): año 2, nº 9, abril, pp. 38-39. En otras palabras, se reconoce cómo las moratorias condicionan la actividad de los jóvenes por procedencia social -y puede asociar a los rockeros con el público lector de Línea-.

46 Ibídem, p. 44.
} 
“desde la alternativa o los caminos 'subterráneos', buscan la posibilidad de expresar sus preocupaciones, de aportar sus ideas y soluciones y en un momento en donde la mediocridad pareció ser el mejor seguro de vida y la más segura posibilidad de acceso al éxito oficial." 47

Insertas en el apartado se reafirma su valor cultural y su condición de canal expresivo de las juventudes. Frente a una música pasatista y una literatura de best sellers superficiales, Línea valora su condición marginal del circuito comercial y la entiende como contraria al mercantilismo promovido desde las esferas oficiales. ${ }^{48}$ Posteriormente, Rosa Ferrer encara específicamente este fenómeno editorial, destaca su ubicación urbana y su carácter excluyente ante la escasez de opciones:

"Pero pese a todo la vigorosa juventud argentina en el caso que nos ocupa, la de las grandes ciudades del país, sobre todo Bs. As., Rosario y Córdoba, ha creado sus mundos subterráneos en donde transmitirse sus mensajes y ayudarse a reconocer el mundo de una forma distinta a la que la pavada comercializada adulta intenta mostrárselo. (...). Sólo en Buenos Aires pululan cerca de un centenar de revistas amorosamente escritas, impresas y divulgadas por muchachos y chicas para sus pares en donde tratan de mostrar, mostrándose, un mundo que las comunicaciones de masas o ya da por conocido o maneja mal o lisa y llanamente oculta." 49

El universo "subte", entonces, compone una reacción juvenil contrapuesta al mundo adulto resignado y supone la gestación de un espacio de intercambio, reconocimiento mutuo, conocimiento y difusión de cuestiones ausentes en la cultura oficial (Margiolakis, 2014; 2016). Este juicio, como sus apreciaciones del movimiento rockero, justifica en una revista política el reconocimiento de una cultura juvenil relativamente autónoma en sus prácticas, modos organizativos y reacciones al contexto existente.

\footnotetext{
47 "Radiografía cultural”, p. 27. En Línea (1981): año 2, nº 10, mayo, pp. 26-7. En el mismo sentido, señala el artículo "Rock y política” que el correlato de los recitales como agrupamientos colectivos es una "increíble cantidad de revistas subterráneas', que pululan en su mayoría por Buenos Aires, pero también por las provincias.” "Rock y política”, p. 8. En Línea (1981): año 2, $\mathrm{n}^{\circ}$ 9, abril, pp. 38-39.

${ }^{48}$ Una crítica a la literatura best seller como sinónimo de la mercantilización cultural, en Alberca, Martín Raúl "¿Leen los argentinos?”. Línea (1980): año 1, $\mathrm{n}^{\circ}$ 7, diciembre, pp. 44-5; “Radiografía cultural, p. 27.Línea(1981): año 2, n 10, mayo, pp. 26-7; Peña Lillo, Arturo:"Del pecado original a la Galaxia Gutenberg”, Línea(1981): año 2, nº 14, septiembre, pp. 42-3.

49 Ferrer, Rosa: "Las revistas de alternativa". Línea (1981): año 2, n 11, junio, p. 37. "Pavada", en el léxico coloquial rioplatense, refiere a una cuestión sin importancia.
} 
En función de esta lectura, Línea convocará seguidamente a varios responsables de revistas "subte" para realizar una entrevista colectiva.50 Con ello muestra su estrategia políticointelectual de interpelar actores culturales, en procura de explorar puntos de coincidencia con su discurso. Del encuentro participan miembros de las revistas Kosmos, La Tecla, Ángel Caído, Celeste, La voz juvenil y Bronca. ${ }^{1}$

$\mathrm{Al}$ contestar inicialmente sobre una definición del término "revista alternativa" -tal como las define Línea-, sus respuestas coinciden en delimitar el abordaje de cuestiones no tratadas por la "prensa oficial” y muestran su identificación colectiva como jóvenes editores (emplean el "nosotros" inclusivo), partícipes de un movimiento que los tiene como protagonistas. Desde ese lugar discursivo, reivindican sus publicaciones como formas de comunicación ajenas a los grandes medios, relacionándolas con el conglomerado de publicaciones similares. En determinados casos se produce una identificación ostensible con el discurso de Línea: los referentes de Celeste y La Tecla retoman elementos discursivos ideológicos de la revista anfitriona, al afirmar que los medios alternativos se tornan "la voz de los que no tienen voz" y antagonizan el "sistema antinacional y desprovisto de valores" imperante. Para algunos de los reporteados, inclusive, el presente comenzaba a habilitar un avance en las condiciones expresivas que podía cambiar el perfil editorial de la "subte":

"Creo que el tema profundo es el paso político que debe dar el Alternativo (sic) ya que, sin cambio político, no habrá cambio ni social, ni cultural. Dentro de la censura, hay un margen, que está dado por la autocensura, pero allí ya no quedan más posibilidades." 52

\footnotetext{
50 “JUVENTUD: sus revistas alternativas”, p. 36. Línea (1981): año 2, n 12, julio, pp. 36-38. Mayúsculas en el original. ${ }^{51}$ Kosmos apareció de 1979 a 1986 y fue dirigida por Daniel Schapces; Bronca (que también es esperanza), de 1980 a fines de 1981 y Mauricio Clansig (y no Clansen, como figura en Línea) fue su secretario de redacción. Celeste fue dirigida por Franco Marletta, que también integraba Bronca. Los tres participan del encuentro. Sobre La voz juvenil, existe una publicación homónima que el catálogo de la biblioteca del Centro de Información y Documentación sobre la Cultura de Izquierdas (CEDINCI) asocia a la Federación Juvenil Comunista durante 1981, si bien esa raigambre no parece del todo verosímil (incluso con atención al posterior acercamiento del PCA al justicialismo en apoyo a la candidatura presidencial de Ítalo Luder-Deolindo Bittel en 1983); por la revista intervienen Claudio Gómez y Ulises (sin mención de apellido). Carecemos de información sobre La Tecla y Ángel caído, representadas según se menciona por Vicente Ruggiero, Roberto Bongiorno y Pablo Diringuer y por Abel Dellacosta, respectivamente. “JUVENTUD: sus revistas alternativas”, p. 36. Línea (1981): año 2, nº 12, julio, pp. 36-38. $5^{2}$ Roberto Bongiorno en ibídem, p. 37.
} 
La pregunta posterior de Línea, en tan sentido, apunta a vincular los emprendimientos "subte" con las inquietudes políticas juveniles y a desligarlos de la referida experiencia generacional de los 70, que califica en torno a la "manipulación juvenil y la subversión". A su vez, las contestaciones subsiguientes tienden a convalidar el tono condenatorio de la revista. $53 \mathrm{La}$ encuesta concluye con el interrogante final a los editores "subte" sobre los partidos políticos, la cuestión nacional y la figura del general Perón. Entre muestras de aquiescencia, resaltan dos opiniones que mantienen distancia del peronismo pero se pronuncian a favor de la constitución de un movimiento multisectorial, consonante con la convocatoria de la Multipartidaria y la prédica favorable de Línea en tal sentido (MULTIPARTIDARIA, 1982; Borrelli y Raíces, 2019).54

Todas estas declaraciones (y medios), que la revista busca presentar como expresión representativa del mundo "subte" - pero que solo constituían una pequeña parte de aquel(Margiolakis, 2014; 2016) dan a simbolizar, también, el pasaje a las responsabilidades de la edad adulta en la transición de la autogestión editorial, la expresión temática de las culturas juveniles y de sus "sensibilidades", a formas de compromiso intelectual. Por consiguiente, las opiniones publicadas demuestran que la politización que se va explicitando en muchas de las revistas "subte" en los primeros años 80, en cierta medida se va sobreimprimiendo a los temas originarios y sus estilos de disidencia. Esto reorientación del foco temático también sintomatiza una creciente fragmentación y diferenciación interna en el movimiento, y sobre este panorama de cambio se monta la revista.

\section{Conclusiones}

Línea se encuadró durante la dictadura en el terreno de la prensa de oposición política, filiada en el peronismo de cuño ortodoxo y en el PJ como su expresión partidaria. Primordialmente, la importancia que dio en sus páginas al análisis cultural desde su número inicial puede asociarse a una lectura de contexto que detectó que el campo de la producción simbólica resultaba una caja de resonancia de la crisis manifestada por el esquema de poder de la dictadura. Una vez culminada la fase más cruenta del terrorismo de estado, con la

\footnotetext{
53 Por orden de cita, declaraciones de Daniel Schapces, Pablo Diringuer, Claudio Gómez y Franco Marletta, “JUVENTUD: sus revistas alternativas”, p. 37. Línea (1981): año 2, nº 12, julio, pp. 36-38.

54 La declaración inicial de la Multipartidaria lleva fecha del 14 de julio de 1981.
} 
debacle económica generalizada y ante los vanos intentos del régimen de asegurarse una futura sucesión política civil que mantuviera la injerencia castrense $-\mathrm{y}$ la impunidad sobre sus crímenes-, diversos actores sociales comenzaron a alzar sus cuestionamientos en torno a la recuperación de las libertades expresivas, el esclarecimiento de la situación de los desaparecidos y el fin de la censura, entre otros tópicos de creciente visibilidad en la agenda pública. La "cultura” y sus actores aparecían enmarcados en ese panorama crítico y suscitaron el interés de Línea. En términos específicos, esta atención se condecía con su pretensión de dar cuenta de la existencia concreta de una "cultura nacional", amenazada por la apertura comercial, la censura y la represión del régimen y relacionada con la identidad sociopolítica peronista que la revista pretendía representar.

Pero, también, la revista alojó enfoques renovados que apuntaron a dar cuenta de la actualidad cultural como parte de las transformaciones sociales de su presente, con el sentido de la productividad en la crisis arriba apuntada. El grado de pluralidad en sus abordajes se condice con una definición relativamente amplia de los componentes sociales, políticos, económicos y culturales del “campo nacional”, que mantenía el discurso opositor en el lugar central.

Así, en un momento de activación social, autores como Juan Sasturain actualizaron la reivindicación de la vitalidad, artística y disidente de ciertas franjas de la producción simbólica ilegítimas para la cultura letrada. Se trataba de una indagación de núcleos disociados de la liberalización económica promovida desde el gobierno militar, relacionados con consumos populares y de las clases medias, y que con la inclusión crítica de sus géneros "marginales" pretendía ampliar el canon de lo culturalmente reconocido. Del mismo modo, alentaba una reconsideración crítica de los medios como espacios donde era posible generar y albergar tales expresiones, por añadidura disidentes con los valores promovidos desde el orden oficial. Esta postura incursionaba en debates académicos precedentes al periodo de estudio y se planteaba, también, en relativa distancia -como hemos visto, conjugada en alguna ocasión con cierto pesimismo político del autor- con una extendida percepción sobre la poderosa influencia mediática en las audiencias, asumida en análisis de otros colaboradores de la revista. En tal sentido, las percepciones "apocalípticas" ejemplificadas en las notas sobre los medios de Pedro García, aparecían influidas con toda probabilidad no por comprobaciones empíricas sino por la contemplación de la situación de la industria cultural en la dictadura, entre la complicidad, el apoyo explícito y los negocios de diverso orden. Por su parte, la obra crítica de Sasturain, como indagación sobre la “cultura nacional”, 
coexistió en la revista con los aportes de otros autores que pretendían definirla, no tanto desde la revisión crítico-conceptual sino con acento en esquemas esencialistas que abrevaban más directamente -en el fondo- en definiciones políticas.

$\mathrm{Al}$ atender modalidades concretas de las prácticas y consumos juveniles urbanos, la revista igualmente demostró un enfoque expandido de las referencias culturales asociadas hasta entonces al peronismo. Algunas referencias a la cultura popular acusan en ella un desajuste y anacronismo, pasible de ser leído en función del intento de defender una identidad cultural (y política) peronista ante los signos de desmantelamiento del estado de bienestar y de su base social, por las reformas estructurales impuestas por la dictadura. Junto a ellas, existe una caracterización del valor artístico específico del rock y de las revistas "subte", y la convocatoria a algunos de sus creadores. Esta tematización demuestra la consideración positiva dela multiforme experiencia juvenil urbana de la época (consumidora, autora, editora, intérprete). Rosa Ferrer y Luis Barroso encarnan particularmente esta última postura desde la crónica y una interpretación cercana al género del ensayo, que en lo inmediato amplía la casuística del repertorio "literario marginal" propuesto por Sasturain. Pero, sobre todo, aprehenden en tal emergencia cultural la potencialidad política que en y de esas manifestaciones podía desprenderse en una etapa histórica de descongelamiento del activismo opositor.

Globalmente, los contenidos culturales de Línea durante 1980-1982 aparecen atravesados por la dinámica coyuntural de declinación de la dictadura y reactivación política. Expresan tanto una referencia identitaria peronista "tradicional" como una apertura a percepciones de la actividad cultural más contemporáneas. Estas lecturas, sus objetos y sujetos de atención, no siempre consistentes entre sí, conviven en sus páginas a partir de su legitimación común bajo el significante "nacional”, que los confrontaba a una inauténtica cultura "de importación" promovida por la dictadura. Aparecen, en consecuencia, fuertemente concernidos por una estrategia de intervención intelectual que se orientaba por los objetivos políticos de la revista en tanto medio opositor. 


\section{Referencias bibliográficas}

ALABARCES, P. (1993): Entre Gatos y Violadores. El rock nacional en la cultura argentina. Buenos Aires: Colihue.

ALABARCES, P., AÑÓN, V. y CONDE, M. (2008): Un destino sudamericano. La invención de los estudios sobre cultura popular en la Argentina. En ALABARCES, P. y RODRÍGUEZ, M. G. (coordinadores), Resistencia y mediaciones. Estudios de cultura popular. Buenos Aires: Paidós, pp. 261-280.

BESOKY, J. L. (2013): La derecha peronista en perspectiva, en Nuevo Mundo Mundos Nuevos. Disponible en: https://journals.openedition.org/nuevomundo/65374 [Consultado: 2 de agosto de 2019].

BORRELLI, M. y RAÍCES, E. (2018): 'Que se vayan'. La revista peronista Línea frente a la dictadura militar a través de sus tapas y contratapas (1980-1982). Revista La Trama de la Comunicación, volumen 22, $\mathrm{n}^{\circ}$ 2, pp. 97-123. Disponible en: www.latrama.fcpolit.unr.edu.ar [Consultado: 24 de agosto de 2019].

(2019): "La revista peronista Línea y la Multipartidaria (1981-1982): unir al "campo nacional' para aislar a la dictadura”. En Quinto Sol, Volumen 23, $\mathrm{n}^{\circ} 1$. Disponible en: http://dx.doi.org/10.19137/qs.v23i1.139o [Consultado: 3 de septiembre de 2019].

CANELO, P. (2008): El proceso en su laberinto: la interna militar de Videla a Bignone. Buenos Aires: Prometeo.

DIEGO, J. L. (2003): Campo intelectual y campo literario en la Argentina (1970-1986). Tesis Doctoral defendida ante la Facultad de Humanidades y Ciencias de la Educación de la Universidad Nacional de La Plata. Director: Dr. Hugo W. Cowes. Disponible en: www.memoria.fahce.unlp.edu.ar [Consultado: 16 de septiembre de 2019].

FIORUCCI, F. (2011): Intelectuales y peronismo, 1945-1955. Buenos Aires: Biblos.

GONZÁLEZ, I. (1991): El diálogo político: la transición que no fue. Buenos Aires: CEDES. 
JENSEN, S. (2005): Vientos de polémica en Cataluña: los debates entre 'los de adentro'y 'los de afuera' de la Argentina de la última dictadura militar. HMiC: història moderna i contemporània Disponible en: http://seneca.uab.es/hmic [Consultado: 16 de septiembre de 2019].

MANSON, E. (2008): José María Rosa. El historiador del pueblo. Buenos Aires: Ciccus.

MARGIOLAKIS, E. (2014): La conformación de una trama colectiva de publicaciones culturales subterráneas durante la última dictadura cívico-militar argentina. Contenciosa, Año II, $\mathrm{n}^{\circ}$ 2, pp. 1-13. Disponible en: http://www.contenciosa.org/ [Consultado: 18 de septiembre de 2019].

(2016): La conformación de una trama de revistas culturales subterráneas en la última dictadura cívico-militar argentina y sus transformaciones en postdictadura. Tesis presentada ante el Doctorado en Ciencias Sociales, Facultad de Ciencias Sociales, UBA. Directora: Dra. Ana Longoni.

MARGULIS, M. y URRESTI, M. (2000): La juventud es más que una palabra, en MARGULIS, M. (editor): La juventud es más que una palabra, Buenos Aires: Biblos, pp. 1330.

MULTIPARTIDARIA (1982): La propuesta de la Multipartidaria. Buenos Aires: El Cid editor.

NEIBURG, F. (1998): Los intelectuales y la invención del peronismo. Buenos Aires: Alianza.

NOVARO, M. y PALERMO, V. (2003): La dictadura militar, 1976-1983. Buenos Aires: Paidós.

OTAL-LANDI, J. (2018): Las raíces revisionistas en la transición democrática: el caso de la revista 'Crear'. Testimonios, año $\mathrm{n}^{\mathrm{0}}$ 7, pp. 88-112. Disponible en: https://revistas.unc.edu.ar/index.php/testimonios/index [Consultado: 26 de septiembre de 2019]. 
PIEDRAS, P. (2005): El cine antiperonista de Lucas Demare y Sixto Pondal Ríos: la reacción liberal. En LUSNICH, A. L. (compiladora): Civilización y barbarie en el cine argentino y latinoamericano. Buenos Aires: Biblos, pp. 85-97.

PUJOL, S. (2007a): Rock y dictadura. Crónica de una generación (1976-1983). Buenos Aires: Booket.

(2007b): Rebeldes y modernos. Una cultura de los jóvenes. En JAMES, D. (director): Nueva Historia Argentina. Violencia, proscripción y autoritarismo, 1955-1976. Buenos Aires: Sudamericana, pp. 281-328.

RAÍCES, E. (2012): Ante 'un acto de locura patriótica'. La revista Línea aborda el conflicto de Malvinas. Question, v. 1, $\mathrm{n}^{\circ}$ 33, pp. 83-89. Disponible en: http://hdl.handle.net/10915/34670 [Consultado: 23 de septiembre de 2019].

(2019): Cultura, medios y política. Humor, Medios \& Comunicación, Línea y la disidencia cultural durante la crisis de la dictadura: 1978-1982. Tesis doctoral defendida ante la Facultad de Ciencias Sociales (UBA). Directora: Dra. Claudia Feld.

RAÍCES, E. y BORRELLI, M. (2016): Un 'juego solitario'. La revista peronista Línea y el 'diálogo político' durante la dictadura militar (1980-1981). Postdata, volumen 21, $\mathrm{n}^{\circ}$ 2, pp. 453-487. Disponible en: http://www.revistapostdata.com.ar/v2/wpcontent/uploads/2016/11/Ra\%C3\%ADces-y-Borrelli-1.pdf [Consultado: 20 de septiembre de 2019].

SABORIDO, J. y BORRELLI, M. (coordinadores) (2011): Voces y silencios: la prensa argentina y la dictadura militar (1976-1983). Buenos Aires: EUDEBA.

SAITTA, S. (2004): Modos de pensar lo social. Ensayo y sociedad en la Argentina (19301965). En NEIBURG, F. y PLOTKIN, M. (editores): Intelectuales y expertos. La constitución del conocimiento social en la Argentina, Buenos Aires, Paidós, pp. 107-146.

VÁZQUEZ, K. (2000): Intelectuales y política: la 'nueva generación' en los primeros años de la Reforma Universitaria. Prismas, $\mathrm{n}^{\circ}$ 4, pp. 59-75. 